EXTENDED REPORT

\title{
A population based case-control study of cataract and inhaled corticosteroids
}

\author{
L Smeeth, M Boulis, R Hubbard, A E Fletcher
}

Br J Ophthalmol 2003;87:1247-1251

See end of article for authors' affiliations

......................

Correspondence to: Dr Liam Smeeth, Department of Epidemiology and Population Health, London School of Hygiene and Tropical Medicine, Keppel Street, London WCIE 7HT, UK;

liam.smeeth@|shtm.ac.uk

Accepted for publication 16 February 2003
Background/aims: Exposure to systemic corticosteroid use is known to be associated with a risk of cataract. Whether low doses of inhaled corticosteroids are associated with an increased risk of cataract is not known. This study was undertaken to quantify the risk of cataract associated with the use of inhaled corticosteroids and assess whether there is a dose-response relation.

Methods: A population based case-control study based on the General Practice Research Database in the United Kingdom. 15479 people with cataract and 15479 controls were matched for age, sex, practice, and observation period.

Results: The crude odds ratio for the association between any recorded exposure to inhaled corticosteroids and cataract was $1.58(95 \% \mathrm{Cl} 1.46$ to 1.71$)$, reduced to $1.10(95 \% \mathrm{Cl} 1.00$ to 1.20$)$ after adjustment for systemic corticosteroid exposure and consultation rate. There was a dose-response relation, the adjusted odds ratio rising from $0.99(95 \% \mathrm{Cl} 0.87$ to 1.13$)$ at daily doses up to $400 \mu \mathrm{g}$ to $1.69(95 \% \mathrm{Cl} 1.17$ to 2.43) for daily doses greater than $1600 \mu \mathrm{g}$. The association was also stronger with increasing duration of use.

Conclusion: Higher doses and longer duration of exposure to inhaled corticosteroids are associated with an increased risk of cataract. The lowest doses compatible with good control of airways disease should be used. The risk of cataract associated with high doses of inhaled corticosteroids needs to be more widely appreciated.
$\mathrm{T}$ he effect of systemic corticosteroid use on the risk of cataract is well established. ${ }^{1}$ Current guidelines recommend the use of inhaled corticosteroids for the majority of people with asthma. ${ }^{2}{ }^{3}$ In the United Kingdom nearly $10 \%$ of people over the age of 65 years have a diagnosis of asthma or chronic obstructive pulmonary disease (COPD), and most of these patients will be prescribed an inhaled corticosteroid at some point. ${ }^{4}$ Currently more than $5 \%$ of the UK population use an inhaled corticosteroid; only antibiotics, analgesics, bronchodilators, and diuretics are prescribed more often. ${ }^{5}$ In the short term high doses of inhaled corticosteroids (up to $2000 \mu \mathrm{g}$ a day) have been shown to have the same impact on adrenal function as $15-30 \mathrm{mg}$ oral prednisolone, ${ }^{6-8}$ so systemic glucocorticoid related adverse effects might be expected. There is also evidence that the long term use of much lower doses of inhaled corticosteroids is associated with systemic adverse effects including bruising, ${ }^{9-11}$ suppression of the hypothalamic-pituitary-adrenal axis, ${ }^{12}{ }^{13}$ reduced bone mineral density, ${ }^{14}{ }^{15}$ and hip fracture. ${ }^{16}$

Cataract is the main cause of low vision and blindness in the world. ${ }^{18}{ }^{18}$ Any common exposure that increases the risk of cataract is thus of great public health importance. We therefore undertook a large case-control study based on the General Practice Research Database to assess the risk of cataract associated with inhaled corticosteroids.

\section{METHODS}

\section{The General Practice Research Database}

The General Practice Research Database (GPRD), previously known as the VAMP Research Bank, was set up in $1987 .{ }^{19}$ It contains complete prescribing and diagnostic information and represents the largest source of continuous data on illness and prescribing habits in the United Kingdom. The practices are broadly representative of all practices in England and Wales in terms of geographical distribution and size and the age and sex distributions of the population included in the GPRD are very similar to the whole UK population. ${ }^{5}$ The data available directly from the database include all drug prescriptions and their indication, a record of every consultation, and of every diagnosis. The information in the GPRD includes details of all prescriptions issued including dosage and quantity. The quality of the information in the database has been validated in a number of independent studies and has been found to be high. ${ }^{19}$ The diagnosis of cataract in the GPRD was validated in a recent study. ${ }^{20}$ Among 262 cases identified from their electronic general practice record, $94 \%$ had their diagnosis confirmed by a review of hospital eye service discharge summaries.

The information obtained from the database is entirely anonymous. Ethical approval for the study was obtained from the Scientific and Ethical Advisory Group of the General Practice Research Database.

\section{Selection of participants}

The source population was all patients currently registered with general practices actively contributing to the GPRD in June 2001, a total of 1441782 people registered with 177 general practices. Eligible cases were defined as any person aged 40 years or more who had a first diagnosis of cataract while registered with a practice participating in the GPRD. The date of the first diagnosis of cataract was the index date, and all participants had to have at least 180 days of observation period before the index date. A random sample of around 15000 cases was selected. For each case, one control with no record of cataract anywhere in their medical record was selected. Controls were alive and registered with the GPRD on the index date of their matched case and were matched on age (within l year), sex, and practice. If the observation periods differed between the cases and matching control the data were truncated to ensure that, within each case-control set, the duration of observation period was the same. 
Table 1 Description of cases and controls and univariate associations

\begin{tabular}{|c|c|c|c|}
\hline & Cases $(n=15479)$ & Controls $(n=15479)$ & Odds ratio $(95 \% \mathrm{Cl})$ \\
\hline Number (\%) female* & $10006(64.6)$ & $10006(64.6)$ & \\
\hline Mean age (years) (SD)* & $75.0(10.0)$ & $75.0(10.0)$ & \\
\hline $\begin{array}{l}\text { Mean observation period } \\
\text { (years) (SD)* }\end{array}$ & $4.5(2.6)$ & $4.5(2.6)$ & \\
\hline \multicolumn{4}{|c|}{ Mean annual consultation rate: } \\
\hline$<2$ & $1898(12.3 \%)$ & $4733(30.6 \%)$ & Baseline \\
\hline 2 to $<5$ & $4467(28.9 \%)$ & $4446(28.7 \%)$ & 2.83 (2.63 to 3.05$)$ \\
\hline 5 to $<8$ & $3879(25.1 \%)$ & $3029(19.6 \%)$ & $3.85(3.56$ to 4.16$)$ \\
\hline$\geqslant 8$ & $5235(33.8 \%)$ & $3271(21.1 \%)$ & 5.06 (4.67 to 5.49$)$ \\
\hline \multicolumn{4}{|r|}{ 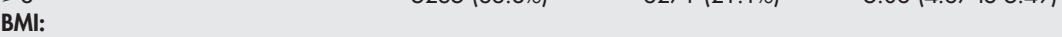 } \\
\hline $15-$ & $2189(14.1 \%)$ & $1718(11.1 \%)$ & Baseline \\
\hline $22-$ & $3022(19.5 \%)$ & $2589(16.7 \%)$ & $0.93(0.85$ to 1.01$)$ \\
\hline $25-$ & $2819(18.2 \%)$ & $2446(15.8 \%)$ & $0.92(0.84$ to 1.00$)$ \\
\hline $28-$ & 2938 (19.0\%) & $2486(16.1 \%)$ & $0.95(0.87$ to 1.03$)$ \\
\hline Missing data & $4511(29.1 \%)$ & $6240(40.3 \%)$ & \\
\hline \multicolumn{4}{|l|}{ Smoking status: } \\
\hline Non-smoker & $9131(59.0 \%)$ & $7801(50.4 \%)$ & Baseline \\
\hline Ex-smoker & $2040(13.2 \%)$ & $1711(11.1 \%)$ & $1.03(0.96$ to 1.11$)$ \\
\hline Current smoker & $2272(14.7 \%)$ & $2082(13.5 \%)$ & $0.96(0.89$ to 1.03$)$ \\
\hline Missing data & $2036(13.2 \%)$ & $3885(25.1 \%)$ & \\
\hline Diabetes & 1735 (11.2) & $790(5.1)$ & 2.37 (2.17 to 2.59$)$ \\
\hline Hypertension & $5028(32.5)$ & $4235(27.4)$ & $1.29(1.23$ to 1.35$)$ \\
\hline Glaucoma & 1125 (7.3) & 577 (3.7) & 2.03 (1.83 to 2.25$)$ \\
\hline Asthma & 1789 (11.6\%) & $1234(8.0 \%)$ & $1.52(1.41$ to 1.65$)$ \\
\hline COPD & $1269(8.2 \%)$ & $887(5.7 \%)$ & $1.49(1.36$ to 1.63$)$ \\
\hline
\end{tabular}

\section{Data processing and analysis}

Data from the electronic records were extracted and set up as a relational data base. Only drug exposure before the index date was included in the analyses.

Inhaled corticosteroid exposure was initially defined as ever or never. Exposure was further categorised as current (participants with at least one prescription within 180 days of the index date) and past (participants with prescriptions greater than 180 days before the index date, but with no recent prescriptions). The mean daily dose of inhaled corticosteroids was categorised as low (up to $400 \mu \mathrm{g}$ a day), moderate (401-800 $\mu \mathrm{g} /$ day), high (80l-1600 $\mu \mathrm{g} /$ day), and very high (greater than $1600 \mu \mathrm{g} /$ day). In addition, the total number of prescriptions for inhaled corticosteroids was extracted. Information about exposure to all other corticosteroid drugs was also extracted, divided into systemic oral, systemic parenteral, ocular, skin, nasal, ear, and other topical (including rectal, vaginal, intra-articular, and intracutaneous). Diagnoses of asthma and chronic obstructive pulmonary disease (COPD) were extracted for descriptive purposes. Data on the following potential confounding factors were extracted: smoking habit; body mass index (weight in kilograms divided by the square of height in metres); diabetes mellitus; and glaucoma. Because frequency of consultation with the general practitioner could affect both the likelihood of a diagnosis of cataract and be associated with drug exposures, consultation rate was considered as a potential confounding factor. The mean annual consultation rate for each participant was calculated, defined as the total number of consultations divided by the years of observation period.

Following the initial descriptive analysis, exposure to inhaled corticosteroids and to all other types of corticosteroids was modelled as a binary ever/never exposures using conditional logistic regression. We then fitted a series of bivariate models, retaining variables that led to a change in the odds ratio for inhaled corticosteroids by $10 \%$ or more. The primary analysis determined the relation between the use of inhaled corticosteroids and the incidence of cataract. We then assessed the effects of different daily doses of and total number of prescriptions for inhaled corticosteroids.

\section{Study power}

Based on a previous study using the same database, we estimated that the prevalence of inhaled steroid use among controls was likely to be at least $5 \% .^{5}$ The study had over $90 \%$ power at the $5 \%$ significance level to detect a minimum relative risk of cataract associated with use of inhaled corticosteroids of 1.25 .

\section{RESULTS}

A total of 15588 people with a diagnosis of cataract were sampled. People with diagnoses of congenital or traumatic cataract were excluded ( 109 cases), leaving 15479 case-control

Table 2 Recorded exposure to different corticosteroids and univariate association with cataract

\begin{tabular}{llll}
\hline Exposure to: & Cases $(\mathbf{n}=15479)$ & Controls (n=15479) & Odds ratio (95\% CI) \\
\hline Inhaled corticosteroid & $1766(11.4 \%)$ & $1180(7.6 \%)$ & $1.58(1.46$ to 1.71$)$ \\
Ocular corticosteroid & $1442(9.3 \%)$ & $725(4.7 \%)$ & $2.12(1.93$ to 2.33$)$ \\
Systemic steroids, oral & $2052(13.3 \%)$ & $1389(9.0 \%)$ & $1.59(1.47$ to 1.71$)$ \\
Systemic steroids, parenteral & $450(2.9 \%)$ & $298(1.9 \%)$ & $1.56(1.34$ to 1.82$)$ \\
Topical steroids, skin & $5729(37.0 \%)$ & $4585(29.6 \%)$ & $1.43(1.36$ to 1.50$)$ \\
Topical steroids, nasal & $1224(7.9 \%)$ & $949(6.1 \%)$ & $1.33(1.21$ to 1.45$)$ \\
Topical steroids, ear & $1020(6.6 \%)$ & $794(5.1 \%)$ & $1.31(1.19$ to 1.45$)$ \\
Topical steroids, other* & $1587(10.2 \%)$ & $1219(7.9 \%)$ & $1.35(1.25$ to 1.46$)$ \\
\hline & & \\
*Rectal, vaginal, dental, intra-articular, and intracutaneous.
\end{tabular}


Table 3 Association between exposure to inhaled corticosteroids and cataract: adjusted models and dose-response relation

\begin{tabular}{|c|c|c|c|c|c|c|}
\hline & \multirow[b]{2}{*}{ Cases $(n=15479)$} & \multirow{2}{*}{$\begin{array}{l}\text { Controls } \\
(n=15479)\end{array}$} & \multirow{2}{*}{$\begin{array}{l}\text { Univariate analysis } \\
\text { Odds ratio }(95 \% \mathrm{Cl})\end{array}$} & \multirow{2}{*}{$\begin{array}{l}\begin{array}{l}\text { Adjusting for } \\
\text { systemic steroids }\end{array} \\
\text { Odds ratio }(95 \% \mathrm{Cl})\end{array}$} & \multicolumn{2}{|c|}{$\begin{array}{l}\text { Adjusting for systemic steroids and } \\
\text { consultation rate }\end{array}$} \\
\hline & & & & & Odds ratio $(95 \% \mathrm{Cl})$ & $p$ Value \\
\hline \multicolumn{7}{|l|}{ Inhaled corticosteroids: } \\
\hline Never & $13713(88.6 \%)$ & 14299 (92.4\%) & Baseline & Baseline & Baseline & \\
\hline Ever & $1766(11.4 \%)$ & $1180(7.6 \%)$ & $1.58(1.46$ to 1.71$)$ & $1.32(1.21$ to 1.44$)$ & $1.10(1.00$ to 1.20$)$ & 0.049 \\
\hline Current & $1319(8.5)$ & $829(5.4)$ & 1.67 (1.53 to 1.83$)$ & 1.39 (1.26 to 1.53$)$ & 1.15 (1.03 to 1.27$)$ & 0.01 \\
\hline Past only & $447(2.9)$ & $351(2.3)$ & 1.35 (1.17 to 1.56$)$ & $1.16(1.00$ to 1.35$)$ & $0.98(0.84$ to 1.14$)$ & 0.8 \\
\hline \multicolumn{7}{|l|}{ Daily dose: } \\
\hline Low (up to $400 \mu \mathrm{g}$ ) & $637(4.1 \%)$ & $496(3.2 \%)$ & $1.36(1.20$ to 1.53$)$ & 1.18 (1.05 to 1.34$)$ & $0.99(0.87$ to 1.13$)$ & $0.002^{*}$ \\
\hline Moderate $(401-800 \mu \mathrm{g})$ & $430(2.8 \%)$ & $264(1.7 \%)$ & 1.73 (1.48 to 2.02$)$ & 1.45 (1.24 to 1.71$)$ & 1.18 (1.00 to 1.39$)$ & \\
\hline High $(801-1600 \mu \mathrm{g})$ & $382(2.5 \%)$ & $221(1.4 \%)$ & $1.82(1.54$ to 2.15$)$ & $1.46(1.23$ to 1.74$)$ & $1.18(0.99$ to 1.42$)$ & \\
\hline Very high $(>1600 \mu \mathrm{g})$ & $117(0.8 \%)$ & $43(0.3 \%)$ & 2.87 (2.02 to 4.08 ) & 2.21 (1.55 to 3.16$)$ & 1.69 (1.17 to 2.43$)$ & \\
\hline Missing data & $200(1.3 \%)$ & $156(1.0 \%)$ & & & & \\
\hline \multicolumn{7}{|l|}{ Number of prescriptions: } \\
\hline No & $13713(88.6 \%$ & $14299(92.4 \%)$ & Baseline & Baseline & Baseline & \\
\hline $1-9$ & 793 (5.1\%) & $589(3.8 \%)$ & 1.41 (1.27 to 1.58$)$ & 1.23 (1.09 to 1.37$)$ & $1.03(0.91$ to 1.16$)$ & $0.004^{*}$ \\
\hline $10-19$ & $373(2.4 \%)$ & $246(1.6 \%)$ & $1.60(1.36$ to 1.89$)$ & 1.33 (1.12 to 1.57$)$ & 1.07 (0.90 to 1.27$)$ & \\
\hline $20-29$ & $210(1.4 \%)$ & $122(0.8 \%)$ & $1.84(1.46$ to 2.30$)$ & 1.50 (1.19 to 1.90$)$ & $1.22(0.96$ to 1.55$)$ & \\
\hline 30-39 & $148(1.0 \%)$ & $88(0.6 \%)$ & 1.76 (1.35 to 2.30$)$ & 1.44 (1.10 to 1.89$)$ & 1.23 (0.93 to 1.62$)$ & \\
\hline$\geqslant 40$ & $242(1.6 \%)$ & $135(0.9 \%)$ & $1.92(1.55$ to 2.39$)$ & 1.55 (1.24 to 1.93$)$ & $1.28(1.01$ to 1.61$)$ & \\
\hline
\end{tabular}

pairs. Descriptive details of cases and controls are shown in Table 1. The mean age of participants was 75.0 years and $64.6 \%$ were female. The mean observation period before the index date was 4.5 years. Cases consulted their general practitioners considerably more often than controls, reflected in the higher mean annual consultation rate. In the crude analyses, both COPD and asthma were associated with an increased risk of cataract.

Table 2 shows the numbers of cases and controls ever exposed to different corticosteroids and the univariate associations between corticosteroid exposure and cataract. The proportions of cases and controls exposed to an inhaled corticosteroid were $11.4 \%$ and $7.6 \%$ respectively. The crude odds ratio for the association between any recorded exposure to inhaled corticosteroids and cataract was 1.58 (95\% CI 1.46 to 1.71 ). In univariate analyses, recorded exposure to any type of corticosteroid was associated with a diagnosis of cataract.

The association between inhaled corticosteroids and cataract was reduced when adjusted for systemic corticosteroid exposure and mean annual consultation rate (Table 3 ). The association was not further affected by adjustment for exposure to ocular or topical corticosteroids, or by adjustment for smoking status, BMI, diabetes mellitus, hypertension, or glaucoma. For any recorded exposure to inhaled corticosteroids, the odds ratio for the association with cataract adjusted for systemic corticosteroid exposure and consultation rate was 1.10 (95\% CI 1.00 to 1.20$)$. The association was stronger for people currently receiving prescriptions for inhaled corticosteroids (within 180 days of the index date) than for people whose prescriptions were all before 180 days before the index date (Table 3). There was evidence for a doseresponse relation, the adjusted odds ratio rising from 0.99 (95\% CI 0.87 to 1.13 ) at daily doses up to $400 \mu \mathrm{g}$ to 1.69 (95\% CI 1.17 to 2.43 ) for daily doses greater than $1600 \mu \mathrm{g}$, $\mathrm{p}=0.002$ for trend. In addition, the association showed a gradient with increasing duration of use, indicated by the total number of recorded prescriptions, $\mathrm{p}=0.004$ for trend.

Controlling for exposure to inhaled corticosteroids, systemic corticosteroids, and for consultation rate wholly explained the association between diagnosed COPD and cataract and between diagnosed asthma and cataract. The adjusted odds ratio for the association between COPD and cataract was 1.03 (95\% CI 0.94 to 1.13 ) compared with a crude odds ratio of 1.49 (see Table 1). The adjusted odds ratio for asthma and cataract was 1.05 (95\% CI 0.95 to 1.16 ) compared with a crude odds ratio of 1.52 (see Table 1).

The numbers of people exposed to individual inhaled corticosteroids are shown in Table 4 . The large majority of people exposed to any inhaled corticosteroid were exposed to beclomethasone only. Of cases exposed to inhaled corticosteroid, $77 \%$ were exposed to beclomethasone only, the corresponding figure for controls was $79.5 \%$. The numbers of people receiving prescriptions for budesonide or fluticasone were low, as were the numbers of participants with prescriptions recorded for more than one type of inhaled corticosteroid. The adjusted odds ratios show that recorded exposure to beclomethasone was associated with a small non-significant increased risk of cataract. Although the odds ratios for the association between exposure to the different

Table 4 Individual inhaled corticosteroids: recorded exposure and association with cataract

\begin{tabular}{|c|c|c|c|c|c|}
\hline \multirow[b]{2}{*}{ Variable } & \multirow[b]{2}{*}{ Cases $(n=15479)$} & \multirow[b]{2}{*}{ Controls $(n=15479)$} & \multirow{2}{*}{$\begin{array}{l}\text { Univariate odds ratio } \\
(95 \% \mathrm{Cl})\end{array}$} & \multicolumn{2}{|c|}{$\begin{array}{l}\text { Adjusted for systemic steroids and } \\
\text { consultation rate }\end{array}$} \\
\hline & & & & odds ratio $(95 \% \mathrm{CI})$ & p Value \\
\hline No inhaled corticosteroic & d $13713(88.59 \%)$ & $14299(92.38 \%)$ & Baseline & & \\
\hline Beclomethasone only & $1359(8.78 \%)$ & $938(6.06 \%)$ & $1.53(1.40$ to 1.67$)$ & 1.08 (0.98 to 1.19$)$ & 0.1 \\
\hline Budesonide only & $181(1.17 \%)$ & $113(0.73 \%)$ & $1.69(1.33$ to 2.14$)$ & $1.16(0.91$ to 1.50$)$ & 0.2 \\
\hline Fluticasone only & $23(0.15 \%)$ & $8(0.05 \%)$ & 3.02 (1.35 to 6.77$)$ & $1.96(0.84$ to 4.56$)$ & 0.1 \\
\hline Mixed & $203(1.31 \%)$ & $121(0.78 \%)$ & $1.76(1.40$ to 2.21$)$ & $1.08(0.85$ to 1.37$)$ & 0.6 \\
\hline
\end{tabular}


types of inhaled corticosteroid and cataract were all positive, none were significant. The levels of exposure were too low to provide adequate power to assess the whether the effects of individual drugs differed.

\section{DISCUSSION}

The results of this study suggest that high doses of inhaled corticosteroids used for prolonged periods are associated with an increased risk of cataract formation. This finding is consistent with the known risk of cataract associated with systemic corticosteroids and the increasing recognition that inhaled corticosteroids, particularly at higher doses, can have systemic effects. ${ }^{21}$ For the relatively small proportion of people prescribed daily doses of $1600 \mu \mathrm{g}$ or more, $41 \%$ of their risk of cataract could be attributed to their exposure to inhaled corticosteroids, assuming the association between exposure and cataract was causal. ${ }^{22}$ We have also shown that while people with a diagnosis of COPD or asthma have around a 50\% increased risk of cataract, the increased risk can be attributed to previous exposure to inhaled and systemic corticosteroids.

Cases included in the study were people with a clinical diagnosis of cataract. It is likely therefore that some people with early cataracts would have been missed and could have been included in the control group. However, there is no reason to suspect this misclassification would be differential with regard to exposure status and thus while there may have been a small reduction in power, this misclassification is unlikely to have biased the effect estimate. A recent study demonstrated a high degree of validity (94\%) for a recorded diagnosis of cataract in the GPRD. ${ }^{20}$ Clinical presentation will be determined largely by a number of factors-firstly, by the severity of the opacity, meaning that diagnosis is one way of assessing the stage of the disease. Cataract is not an all or nothing disease: there is a continuous spectrum of severity from blinding cataract to minor opacities that would only be found on detailed examination. Using clinical presentation as an indicator of severity is in line with modern epidemiological thinking about risk factors: assessing how much disease is present rather than whether there is any or none. The second factor likely to determine clinical diagnosis is frequency of clinic attendance. We were able to control for the confounding effect of consultation rate on the association between inhaled corticosteroids and diagnosed cataract. The third important factor determining the stage of clinical presentation relates to the healthcare provider. In this study cases and controls were matched on general practice (primary care clinic) reducing the chance of systematic differences in the ascertainment of cataract between the two comparison groups. We had no information about type of cataract. However, the large numbers of cases and the mixed population in this study mean we would have had a representative mix of different types of cataract. The important issues both for individuals and for public health involve the risks associated with having any type of cataract, not a specific subcategory. Cases were selected from the existing cohort of patients within the GPRD using simple random sampling so there was no potential for selection bias.

The levels of missing data for smoking and BMI were higher among controls than among cases. For both cases and controls, well over half the people with missing data were in the lowest category for consultation rate. This is as expected: people who attended the doctor less were less likely to have their smoking status and BMI recorded. Controls were more likely to be in the lowest category for consultation rate, and were therefore more likely to have missing data from smoking and BMI. The observed lack of association between cataract and current or ex-smoking is inconsistent with smoking being an established risk factor for the disease. ${ }^{23}$
While the prevalence of current smoking is consistent with that recorded in a large representative household survey in the United Kingdom, the level of ex-smoking is much lower than would be expected. ${ }^{24}$ We have previously shown that for people recorded as being current smokers, the magnitude and direction of the dose-response relation with the risk of lung cancer are what would be expected, ${ }^{25}$ suggesting that a code for current smoking is accurate. A likely explanation for the observed lack of association between cataract and either current or ex-smoking when compared with non-smoking is that many people recorded as being non-smokers are in fact ex-smokers. It is possible that we failed to completely control for confounding by smoking in the association between inhaled corticosteroids and cataracts. However, when the analysis was restricted to smokers only, the association between any exposure to inhaled corticosteroids and cataracts was virtually identical to the result for all participants (adjusted odds ratio for all participants 1.10 and for smokers only 1.12). In addition, the dose-response relation between inhaled corticosteroid exposure and cataract remained and was similar to that seen for all participants. It is therefore unlikely that residual confounding by smoking explained the observed association between inhaled corticosteroid exposure and cataract.

Prescription data were recorded before the subject became a case so there was no potential for recall bias. Drug prescriptions from practices participating in the GPRD are generated by the practice computers ensuring the accuracy of the electronic prescribing records. We lacked information about drug exposures before participants registered with the General Practice Research Database and it is possible that we may not have been able to fully control for systemic corticosteroids prescribed in the years before data collection started. In addition, our estimate of exposure was based on drugs prescribed rather than drugs known to have been taken. While this may have led to a small degree of misclassification of exposure status, there is no reason to suspect this would be differential with regard to diagnosis and thus while there may have been a small reduction in power, any such misclassification is unlikely to have biased the effect estimate.

A previous smaller study using the GPRD has also assessed the risk of cataract associated with the use of inhaled corticosteroids. $^{26}$ This study included only 1194 cases compared with the 15479 included in our study, and was based on an earlier version of the GPRD. Importantly, this study did not control for the effects of consultation rate, demonstrated in our study to be an important confounder. Despite this, however, the results of this study, and two other major clinical studies, are consistent with our findings of an increased risk of cataract associated with inhaled steroids..$^{27}$

High doses and prolonged use of inhaled corticosteroids are associated with an increased risk of cataract independent of exposure to other types of corticosteroid medications. This risk adds to the growing literature on the potential for adverse effects from the use of inhaled corticosteroids. These risks need to be considered in the light of the large beneficial effects value of inhaled corticosteroids to many patients with asthma and to some patients with chronic obstructive pulmonary disease. While lower doses have not been shown to be completely without risk, there is good evidence to suggest that lower doses are associated with a reduced risk of adverse effects. The risk of cataract associated with high doses of inhaled corticosteroids needs to be more widely recognised.

\section{ACKNOWLEDGEMENTS}

We would like to thank Chris Smith for help with data processing. 


\section{Authors' affiliations}

L Smeeth, M Boulis, A E Fletcher, Department of Epidemiology and Population Health, London School of Hygiene and Tropical Medicine, Keppel Street, London WC1E 7HT, UK

R Hubbard, Division of Respiratory Medicine, University of Nottingham, Clinical Sciences Building, Nottingham City Hospital, Nottingham NG5 IPB, UK

The study was funded by the Gift of Thomas Pocklington. Liam Smeeth is supported by an MRC clinical scientist fellowship. Richard Hubbard is supported by a Wellcome Trust advanced fellowship.

\section{REFERENCES}

1 Urban RC Jr, Cotlier E. Corticosteroid-induced cataracts. Surv Ophthalmol 1986;31:102-10.

2 British Thoracic Society. Guidelines on the management of asthma. Thorax 1993:48:s 1-s24.

3 National Asthma Education and Prevention Program Expert Panel. Guidelines for the Diagnosis and Management of Asthma. Update on selected topics 2002. Bethesda: National Institutes of Health, 2002.

4 Roberts SJ, Bateman DN. Which patients are prescribed inhaled anti-asthma drugs? Thorax 1994;49:1090-5.

5 Office for National Statistics. Key health statistics from general practice 1996 (Series MB6 No. 1). London: Office for National Statistics, 1998

6 Toogood JH, Baskerville J, Jennings B, et al. Bioequivalent doses of budesonide and prednisone in moderate and severe asthma. J Allergy Clin Immunol 1989;84:688-700

7 Jennings BH, Andersson KE, Johansson SA. Assessment of systemic effects of inhaled glucocorticosteroids: comparison of the effects of inhaled budesonide and oral prednisolone on adrenal function and markers of bone turnover. Eur J Clin Pharmacol 1991;40:77-82.

8 Meijer RJ, Kerstiens HA, Arends LR, et al. Effects of inhaled fluticasone and oral prednisolone on clinical and inflammatory parameters in patients with asthma. Thorax 1999:54:894-9.

9 Geddes DM. Inhaled corticosteroids: benefits and risks. Thorax 1992;47:404-7.

10 Pauwels RA, Lofdahl CG, Laitinen LA, et al. Long-term treatment with inhaled budesonide in persons with mild chronic obstructive pulmonary disease who continue smoking. N Engl J Med 1999:340:1948-53.

11 Burge PS, Calverley PM, Jones PW, et al. Randomised, double blind, placebo controlled study of fluticasone propionate in patients with moderate to severe chronic obstructive pulmonary disease: the ISOLDE trial. $B M$ 2000;320:1297-303

12 Boorsma M, Andersson N, Larsson P, et al. Assessment of the relative systemic potency of inhaled fluticasone and budesonide. Eur Respir J 1996:9:1427-32.

13 Donnelly $\mathbf{R}$, Williams $K M$, Baker $A B$, et al. Effects of budesonide and fluticasone on 24-hour plasma cortisol. A dose-response study. Am J Respir Crit Care Med 1997; 156:1746-51.

14 Wong CA, Walsh $\amalg$, Smith CJ, et al. Inhaled corticosteroid use and bonemineral density in patients with asthma. Lancet 2000;355:1399-403.

15 The Lung Health Study Research Group. Effect of inhaled triamcinolone on the decline in pulmonary function in chronic obstructive pulmonary disease. N Engl J Med 2000;343:1902-9.

16 Hubbard R, Smith C, Smeeth L, et al. Inhaled corticosteroids and hip fracture: a population-based case-control study. Am J Respir Crit Care Med 2002;166:1563-6

17 World Health Organization Office of Information. Blindness and visual disability: Part 2: Major causes worldwide. WHO fact sheet 143. Geneva: WHO, 1997.

18 Dolin P. Epidemiology of cataract. In: Johnson GJ, Minassian DC, Weale R, eds. The epidemiology of eye disease. London: Chapman and Hall, 1998:103-18.

19 Walley T, Mantgani A. The UK General Practice Research Database. Lancet 1997:350:1097-9.

20 Ruigomez A, Garcia Rodriguez LA, Dev VJ, et al. Are schizophrenia or antipsychotic drugs a risk factor for cataracts? Epidemiology 2000;11:620-3.

21 Lipworth BJ. Systemic adverse effects of inhaled corticosteroid therapy: a systematic review and meta-analysis. Arch Intern Med 1999:159:941-55.

22 Cole P, MacMahon B. Attributable risk percent in case-control studies. Br J Prev Soc Med 1971;25:242-4

23 Christen WG, Glynn RJ, Ajani UA, et al. Smoking cessation and risk of agerelated cataract in men. JAMA 2000;284:713-6.

24 Office for National Statistics. Living in Britain: preliminary results from the 1996 general household survey. London: Stationery Office, 1997.

25 Hubbard R, Venn A, Lewis S, et al. Lung cancer and cryptogenic fibrosing alveolitis. A population-based cohort study. Am J Respir Crit Care Med 2000;161:5-8

26 Jick SS, Vasilakis-Scaramozza C, Maier WC. The risk of cataract among users of inhaled steroids. Epidemiology 2001;12:229-34.

27 Cumming RG, Mitchell P, Leeder SR. Use of inhaled corticosteroids and the risk of cataracts. N Engl J Med 1997;337:8-14.

28 Garbe E, Suissa S, Lelorier J. Association of inhaled corticosteroid use with cataract extraction in elderly patients. JAMA 1998;280:539-43. 